Grand Valley State University

ScholarWorks@GVSU

\title{
Reactions to Participating in Dating Violence Research: Are Our Questions Distressing Participants?
}

\author{
Ryan C. Shorey \\ University of Tennessee - Knoxville, rshorey@utk.edu \\ Tara L. Cornelius \\ Grand Valley State University, cornelta@gvsu.edu \\ Kathryn M. Bell \\ Northern Illinois University
}

Follow this and additional works at: https://scholarworks.gvsu.edu/psy_articles

Part of the Psychology Commons

\section{ScholarWorks Citation}

Shorey, Ryan C.; Cornelius, Tara L.; and Bell, Kathryn M., "Reactions to Participating in Dating Violence Research: Are Our Questions Distressing Participants?" (2011). Peer Reviewed Articles. 17.

https://scholarworks.gvsu.edu/psy_articles/17

This Article is brought to you for free and open access by the Psychology Department at ScholarWorks@GVSU. It has been accepted for inclusion in Peer Reviewed Articles by an authorized administrator of ScholarWorks@GVSU.

For more information, please contact scholarworks@gvsu.edu. 
Reactions to

Participating in

Dating Violence

Research: Are Our

Questions Distressing

Participants?
Journal of Interpersonal Violence 26(I4) 2890-2907

(C) The Author(s) 2011

Reprints and permission: http://www. sagepub.com/journalsPermissions.nav DOI: I0.I |77/08862605I0390956 http://jiv.sagepub.com

\author{
Ryan C. Shorey, ' Tara L. Cornelius, ${ }^{2}$ \\ and Kathryn M. Bell ${ }^{3}$
}

\begin{abstract}
In recent years, there has been increased research focus on dating violence, producing important information for reducing these violent relationships. Yet Institutional Review Boards (IRBs) are often hesitant to approve research on dating violence, citing emotional distress of participants as a possible risk of participation. However, no known research has examined the reactions of research participants to questions about dating violence. The current study examined the reactions among college students to completing a self-report measure on dating violence. Results showed that participants reported numerous positive experiences as a result of their research participation, with only mildly increased negative emotional reactions evident for some. Findings are discussed in relation to IRB proposals and appropriate informed consent for research participants.
\end{abstract}

\footnotetext{
'University of Tennessee, Knoxville

${ }^{2}$ Grand Valley State University, Allendale, MI

${ }^{3}$ Northern Illinois University, DeKalb

Corresponding Author:

Ryan C. Shorey, University of Tennessee, I404 Circle Dr., Austin Peay Building,

Knoxville, TN 37996

Email: rshorey@utk.edu
} 


\section{Keywords}

violence, dating, aggression, research ethics

Dating violence is a serious and prevalent problem. Dating violence includes psychological, physical, and sexual aggression (Shorey, Cornelius, \& Bell, 2008), and research indicates that the majority of college students will be victimized by a dating partner prior to graduation (Smith, White, \& Holland, 2003; White \& Smith, 2009). In addition, dating violence is largely bidirectional (Cornelius, Shorey, \& Beebe, 2010) and minor in severity and frequency (Shorey et al., 2008), similar to a situational couple violence typology (Johnson \& Leone, 2005). Still, male and female victims of dating violence are at increased risk for mental health problems, such as depression and anxiety (Kaura \& Lohman, 2007). In recent years, there has been an increased research focus on dating violence that has resulted in an improved understanding of these violent relationships (Shorey et al., 2008), providing information that has been used in prevention programming aimed at the amelioration of dating violence (e.g., Wolfe et al., 2003).

Although research on dating violence has increased substantially in recent years and yielded important information for researchers and clinicians, it has been our experience that Institutional Review Boards (IRBs) are often hesitant to approve research on dating violence, expressing concern that emotional distress may result from answering questions on violence. Indeed, Newman and Kaloupek (2004) stated "It is likely that a nearly universal concern of IRBs is the potential for emotional harm due to recall of traumatic events" (p. 390). IRBs are designed to ensure the protection and ethical treatment of research participants (Hirshon et al., 2002), and this is especially important for vulnerable populations such as victims of violence (Logan, Walker, Shannon, \& Cole, 2008). However, IRBs have historically had to make decisions on the ethics of research proposals and protection of human subjects based on personal opinions and subjective data, as there is often a lack of scientific, objective research on the risks and benefits of trauma-related research (Carter-Visscher, Naugle, Bell, \& Suvak, 2007). Consistent with this lack of research on the risks and benefits of trauma-related research, investigators have yet to examine whether dating violence research participants report increased emotional harm, whether they perceive drawbacks to their participation, or if they perceive benefits from participation. Knowing this information is important because it can guide researchers and IRBs in implementing proper protections from harming participants and aid in the accurate disclosure of possible risks and benefits to research participants. 
Although research is lacking on the reactions of participants to dating violence studies, there is some research on the reactions of other traumatized populations. For example, research with adult women who met diagnostic criteria for posttraumatic stress disorder (PTSD) showed that a lengthy assessment that included self-report measures, interviews, and psychophysiological measurement was not overly distressing (Resick, Iverson, \& Artz, 2009). In fact, participation in the assessment was generally perceived as interesting, and most women reported they would be willing to participate in similar research studies. Still, a few women reported increased distress associated with their research participation. In addition, Campbell, Adams, Wasco, Ahrens, and Sefl (2010) examined the reactions to research participation among female rape survivors. After completing in-depth interviews and self-report measures on their trauma experience and psychological functioning, the vast majority of women reported having a positive, insightful research experience. In their review of existing literature on the reactions of research participants to trauma-related research, Newman and Kaloupek (2004) found that, although some participants do experience distress and strong negative emotional reactions to their research participation, most participants view their participation favorably and do not regret their participation. Overall, the majority of these research findings suggest that most trauma-related research participants appear to have a favorable costbenefit ratio to research participation (Newman \& Kaloupek, 2004).

Several researchers have also examined reactions to self-reported violence research among battered women, showing that the vast majority of women find their participation interesting and valuable, not distressing (Griffin, Resick, Waldrop, \& Mechanic, 2003). Yet some women did report that they became upset by their participation and even regretted participating (Johnson \& Benight, 2003). Generalizing these findings to individuals who have experienced dating violence, however, is difficult as it is possible that reactions to disclosing information about traumatic events may differ across types of traumas. First, the majority of the women in these studies were recruited from domestic violence shelters, which suggests that they had experienced relatively severe abuse. Dating violence is commonly experienced as minor violence and rarely as severe (Shorey et al., 2008). Second, the women in the above studies were help seeking, making it likely that they were aware that they would need to disclose their abusive experiences to others (i.e., an advocate, police, etc.). In contrast, dating violence research samples are largely drawn from university research subject pools, not from help-seeking locations. It is plausible that university participants may not anticipate disclosure of violent experiences in the context of research participation and, thus, the level of distress may differ from that of a help-seeking population. 
Therefore, the purpose of the present study was to examine the reactions among college students to participating in research on dating violence. We chose to examine differences among individuals reporting dating violence experiences versus individuals not reporting dating violence experiences on their reactions to research participation. We also examined whether individuals reporting more frequent dating violence victimization/perpetration had different research reactions than individuals reporting less frequent victimization/ perpetration. Based on research with battered women and other traumatized populations, it was hypothesized that victims, relative to nonvictims, and perpetrators, relative to nonperpetrators, would report more personal benefits (e.g., gained insight), participation benefits (e.g., glad they were able to participate), and more positive global evaluations of the research (e.g., research was for a good cause) relative to nonvictims. It was also hypothesized that victims would report more negative emotional reactions (e.g., became emotional during the research) and perceive more drawbacks to their research participation (e.g., questions were too personal) than nonvictims. Last, we expected individuals reporting more frequent dating violence victimization or perpetration to report more negative emotional reactions, perceive more drawbacks, but also to endorse more positive research experiences than individuals reporting less frequent dating violence victimization or perpetration. To guard against individuals reporting more positive research reactions solely for socially desirable purposes, we controlled for the influence of social desirability in all analyses.

\section{Method}

\section{Participants}

A sample of undergraduate students from a large, public, Midwestern university participated in the current study. Participants were recruited from introductory psychology classes and received "enrichment" credits that contributed to their grade in the course. To include a sufficient number of participants who had experienced dating violence, data from two studies were combined. The first study required participants to have been in a dating relationship at some point in their lives and be 18 years of age or older $(n=196)$. The second study not only required participants to be 18 years of age or older but also required them to have perpetrated at least one act of physical aggression in the past 6 months against a dating partner $(n=70)$. No demographic differences were evident between samples, which justified combining them for the purpose of this study. 
As a few participants had incomplete data $(n=6)$, these cases were removed from the current analyses, making the final sample size 260 . Of these participants, $70.4 \%$ were female, consistent with the enrollment patterns of introductory psychology courses at this university and past research from this university (e.g., Cornelius, Sullivan, Wyngarden, \& Milliken, 2009). The mean age of participants was $18.7(S D=2.12)$. Self-identified ethnic/racial background consisted of $90.4 \%$ non-Hispanic White, 3.1\% African American, $2.3 \%$ Asian, $2.7 \%$ Hispanic, and $1.2 \%$ identified as Other. The majority of participants, $97.7 \%$, identified as heterosexual, and the mean length in months of a current dating relationship was $17.4(S D=15.19)$.

\section{Procedure}

For the first study, participants completed the measures of interest in a large room with approximately 20 participants per session. All students had at least one seat separating them from the next person. For the second study, participants completed the measures of interest alone in a private room with only a research assistant present. Completion of these measures for both studies generally took less than 1 hour. After completing all measures, participants were given a debriefing form which included referral resources for domestic violence services and counseling and received the enrichment credits for their psychology course. Both studies were reviewed and approved by the IRB of the university where data collection took place.

\section{Materials}

Demographic questionnaire. This demographic questionnaire asked participants their age, gender, relationship status, ethnicity, and length of their dating relationship.

Relationship aggression. The Revised Conflict Tactics Scale (CTS2; Straus, Hamby, Boney-McCoy, \& Sugarman, 1996) was used to examine aggression that had occurred in participants' dating relationships. The CTS2 allows participants to rate $(1=$ once; $6=$ more than 20 times $)$ the number of times a particular conflict tactic was used by both the participant and his/her partner in the previous year. Higher scores on the CTS2 correspond with more frequent violence perpetration/victimization. The internal consistency of the CTS2 is well documented, ranging from .79 to .95 , and it has good construct and discriminate validity (Straus et al., 1996).

Social desirability. The Marlowe-Crowne Social Desirability Scale (MCSDS; Crowne \& Marlowe, 1960) was used to examine participants' socially desirable 
responding. The MCSDS contains 33 items, and participants are asked to indicate if each item is "true" or "false." Higher scores on the MCSDS indicate greater socially desirable responding. Internal consistency of the MCSDS is good at .88 (Crowne \& Marlowe, 1960).

Research reactions. The Reactions to Research Participation Questionnaire (RRPQ; Newman, Willard, Sinclair, \& Kaloupek, 2001) was used to examine individuals' reactions to participating in the two research projects. The RRPQ contains 23 items about reactions to research participation and contains five subscales. The Participation Factor (PF) subscale assesses cost-benefit ratios, the Personal Benefits (PB) subscale assesses perceived personal insight, the Emotional Reactions (ER) subscale assesses negative ER, the Perceived Drawbacks (PD) subscale assesses drawbacks such as whether the questions were too personal, and the Global Evaluation (GE) subscale assesses faith in confidentiality and the researcher's respect for the individual. Items are rated on a 5-point scale ( 1 = strongly disagree; $5=$ strongly agree $)$, and higher scores indicate more positive evaluations. That is, a high score on PF indicates more positive participation experiences, a high score on PB indicates more positive personal insight, a high score on ER indicates less negative emotions associated with research participation, a high score on PD indicates less drawbacks to research participation, and a high score on GE indicates greater confidence in the research. Internal consistency estimates for all five subscales range from .72 to .87 (DePrince \& Chu, 2008). Participants completed this measure following completion of the CTS2 and MCSDS.

\section{Results}

Due to the CTS2 physical and sexual aggression subscales being positively skewed, log transformations were performed on these subscales to normalize their distributions prior to analyses. Table 1 presents descriptive statistics, bivariate correlations, and mean differences between men and women. For men, psychological and physical victimization and psychological perpetration were positively associated with $\mathrm{PF}$ and $\mathrm{PB}$, and physical perpetration was positively associated with $\mathrm{PB}$. In addition, psychological and physical aggression perpetration and victimization, and sexual victimization, were negatively associated with ER from the research. For women, reports of dating violence were not significantly correlated with any of the RRPQ subscales.

Due to gender differences in the association between dating violence and the RRPQ subscales, differences between victims/nonvictims and perpetrators/ nonperpetrators were examined separately for men and women. For each form of aggression, individuals who endorsed at least one item of victimization were 


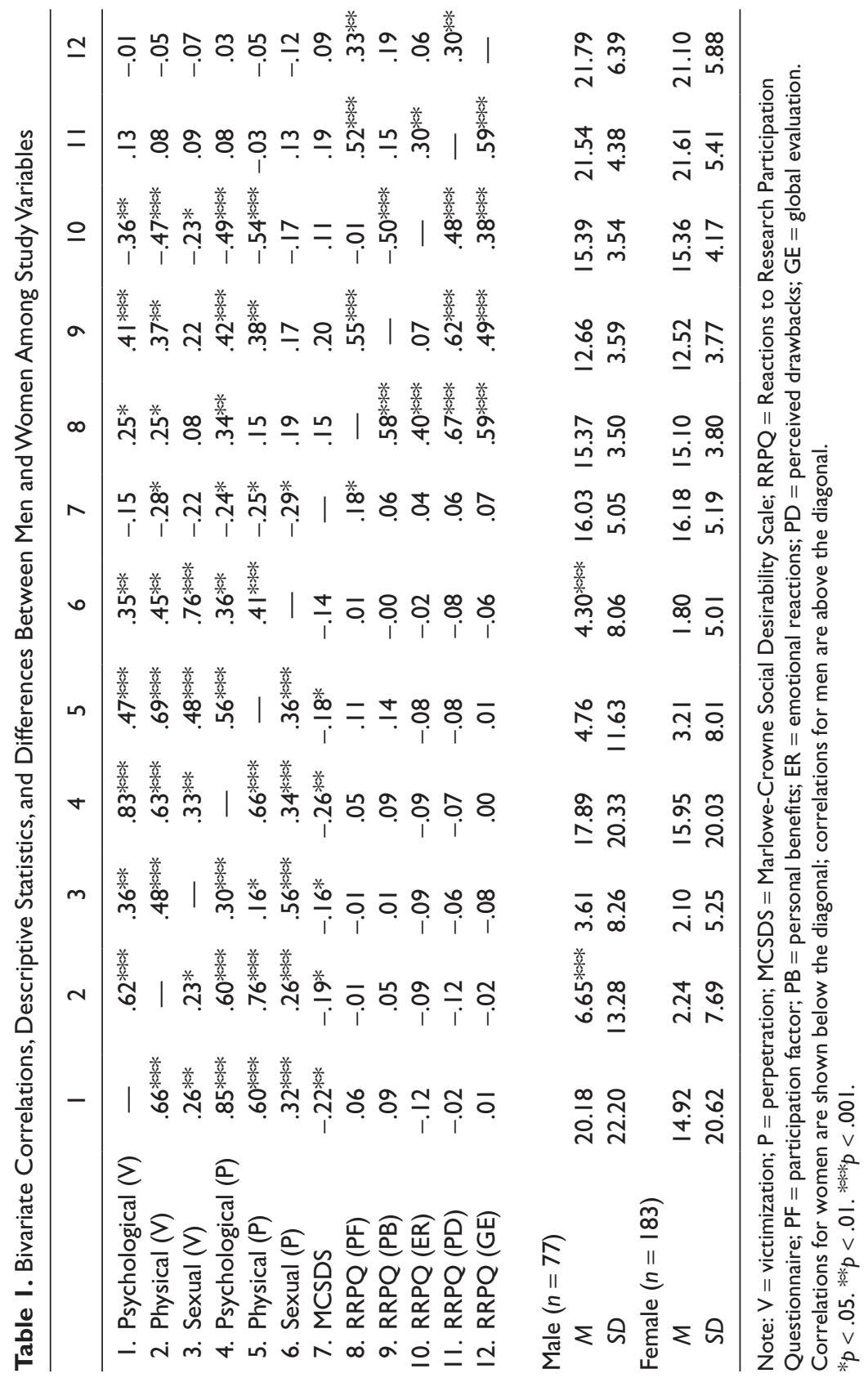


considered victims, and individuals who endorsed at least one item of perpetration were considered perpetrators. This is consistent with other research that has used the same method to categorize victims and perpetrators of dating violence (e.g., Hines \& Saudino, 2003; Rhatigan \& Street, 2005). To control for the effects of social desirability on reports of research reactions, analyses of covariance (ANCOVAs) were employed with social desirability as the covariate. As displayed in Table 2, female victims of psychological aggression reported more positive research PFs than nonvictims, $F(1,180)=4.180$, $p<.05$, and female victims of physical aggression perceived more drawbacks from their research participation than nonvictims, $F(1,180)=4.246, p<.05$.

For men, victims of psychological aggression reported more positive PB, $F(1,74)=6.136, p<.05$, and more mildly negative ER than nonvictims, $F(1,74)=5.107, p<.05$. Victims of physical aggression reported more positive PB, $F(1,74)=15.167, p<.001$, more positive PFs, $F(1,74)=6.491, p<.05$, and more mildly negative ER to research participation than nonvictims, $F(1,74)=14.642, p<.001$ (see Table 2).

Next, differences between perpetrators and nonperpetrators were examined and are displayed in Table 3. Female perpetrators of psychological, $F(1,180)=5.212, p<.05$, and physical aggression, $F(1,180)=4.375$, $p<.05$, reported more positive PFs than nonperpetrators. In addition, perpetrators of physical aggression reported more positive PB than nonvictims, $F(1,180)=5.696, p<.05$. Last, female perpetrators of sexual aggression perceived more drawbacks to their research participation than nonperpetrators, $F(1,180)=5.089, p<.05$.

Male perpetrators of psychological, $F(1,74)=4.101, p<.05$, and physical aggression, $F(1,74)=10.056, p<.01$, reported more positive $\mathrm{PB}$ relative to nonperpetrators, and perpetrators of physical aggression reported more mildly negative ER than nonperpetrators, $F(1,74)=18.132, p<.001$. Finally, male perpetrators of sexual aggression reported more positive PFs than nonperpetrators, $F(1,74)=4.689, p<.05$, and less $\mathrm{PD}, F(1,74)=4.072, p<.05$.

We also sought to examine whether victims/perpetrators reporting more frequent aggression had different research participation reactions than victims/ perpetrators reporting less frequent aggression. To examine these differences, a median split was computed for each subtype of aggression. Individuals above the median were considered victims/perpetrators reporting more frequent aggression, and individuals at or below the median were considered victims/perpetrators reporting less frequent aggression. Individuals above the median had significantly more perpetration/victimization exposure than individuals below the median on all three types of aggression, and this held true for both males and females. ${ }^{1}$ As with the above analyses, ANCOVAs were 
Table 2. Differences Between Victims and Nonvictims on RRPQ Subscales

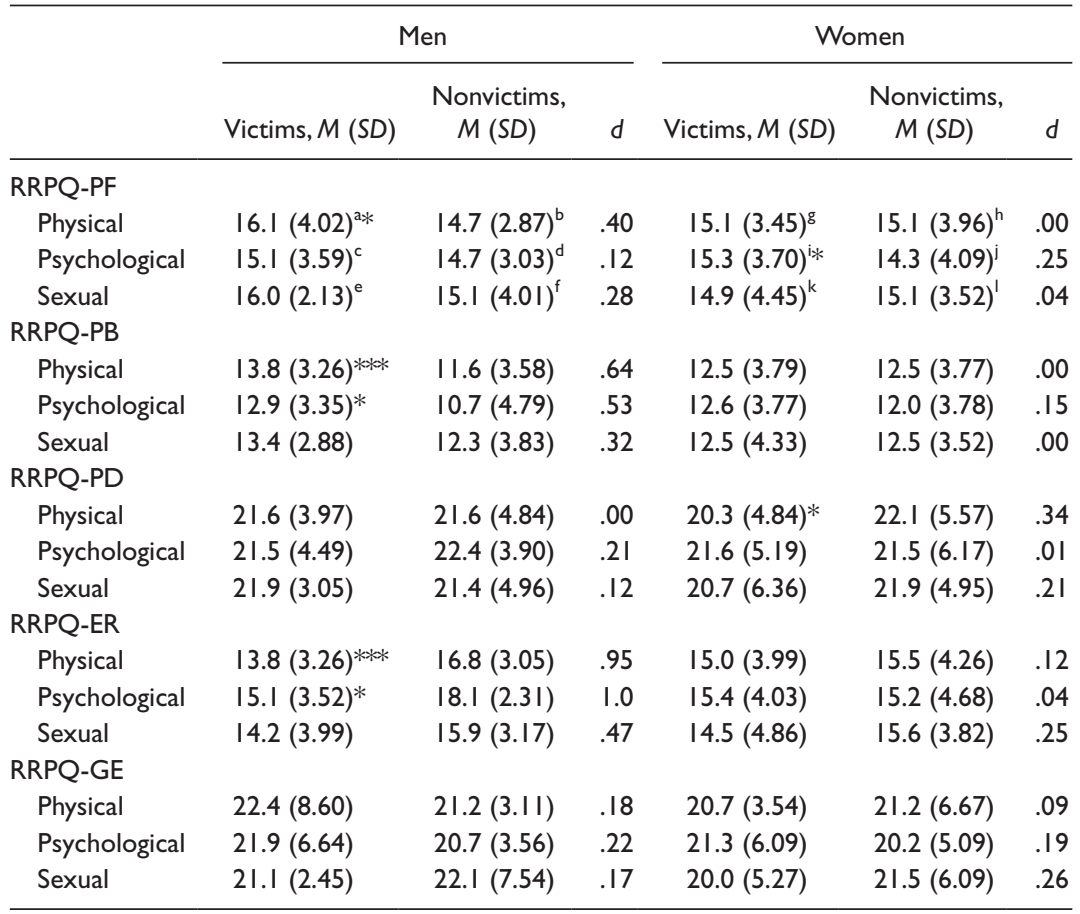

Note: RRPQ = Reactions to Research Participation Questionnaire; PF $=$ participation factor; $\mathrm{PB}=$ personal benefits; PD = perceived drawbacks; $E R=$ emotional reactions; $\mathrm{GE}=$ global evaluation.

a. $n=37$; b. $n=40$; c. $n=68$; d. $n=9$; e. $n=25$; f. $n=52$; g. $n=56$; h. $n=127$; i. $n=141$; j. $n=42$; k. $n=54$;

I. $n=129 ; *_{p}<.05 . * * p<.01 . * * * p<.001$.

employed with social desirability as a covariate to examine differences between low- and high-aggression groups.

As displayed in Table 4, male perpetrators reporting more frequent psychological aggression reported more positive PFs, $F(1,64)=10.368, p<.01$, and $\mathrm{PB}, F(1,64)=5.829, p<.05$, but more negative ER, $F(1,64)=4.100$, $p>.05$, than perpetrators reporting less frequent psychological aggression. For physical aggression, perpetrators of more frequent aggression reported more positive $\mathrm{PB}, F(1,30)=12.116, p<.01$, but more negative ER, $F(1,30)=$ $5.505, p<.05$, than perpetrators reporting less frequent physical aggression. No differences were evident for low- and high-frequency sexual perpetrators on any of the RRPQ subscales. 
Table 3. Differences Between Perpetrators and Nonperpetrators on RRPQ Subscales

\begin{tabular}{|c|c|c|c|c|c|c|}
\hline & \multicolumn{3}{|c|}{ Men } & \multicolumn{3}{|c|}{ Women } \\
\hline & $\begin{array}{l}\text { Perpetrators, } \\
M(S D)\end{array}$ & $\begin{array}{c}\text { Nonperpetrators, } \\
M(S D)\end{array}$ & $d$ & $\begin{array}{l}\text { Perpetrators, } \\
M(S D)\end{array}$ & $\begin{array}{c}\text { Nonperpetrators, } \\
M(S D)\end{array}$ & $d$ \\
\hline \multicolumn{7}{|l|}{ RRPQ-PF } \\
\hline Physical & $16.0(4.73)^{\mathrm{a}}$ & $14.9(2.17)^{b}$ & .29 & $15.6(3.03)^{g *}$ & I $4.7(4.23)^{\mathrm{h}}$ & .24 \\
\hline Psychological & $15.5(3.62)^{c}$ & $14.8(2.86)^{d}$ & .21 & $15.3(3.65)^{i *}$ & $14.0(4.42)^{\mathrm{j}}$ & .32 \\
\hline Sexual & $16.1(3.14)^{\mathrm{e} *}$ & $14.8(3.75)^{f}$ & .37 & $14.5(5.22)^{k}$ & $15.2(3.29)^{\prime}$ & .16 \\
\hline \multicolumn{7}{|l|}{ RRPQ-PB } \\
\hline Physical & I $3.8(3.44)^{* * *}$ & II.8 (3.48) & .57 & $13.2(3.37)^{*}$ & $12.0(3.95)$ & .32 \\
\hline Psychological & $12.9(3.35)^{*}$ & II.3 (4.80) & .38 & $12.6(3.64)$ & 11.8 (4.33) & .20 \\
\hline Sexual & $13.0(3.27)$ & $12.3(3.84)$ & .19 & $11.9(4.45)$ & $12.6(3.55)$ & .17 \\
\hline \multicolumn{7}{|l|}{ RRPQ-PD } \\
\hline Physical & $21.4(4.66)$ & 21.7 (4.27) & .06 & $21.3(4.3 \mathrm{I})$ & $21.7(6.08)$ & .07 \\
\hline Psychological & $21.4(4.52)$ & $22.5(3.68)$ & .26 & $21.8(5.10)$ & $20.3(6.68)$ & .25 \\
\hline Sexual & $22.3(4.13)^{*}$ & 20.9 (4.59) & .32 & $19.8(6.97)^{*}$ & 22.1 (4.78) & .38 \\
\hline \multicolumn{7}{|l|}{ RRPQ-ER } \\
\hline Physical & I $3.5(3.56)^{* k *}$ & $16.8(2.82)$ & 1.0 & I5.I (3.54) & I5.5 (4.57) & .09 \\
\hline Psychological & $15.0(3.54)$ & $17.7(2.54)$ & .87 & $15.5(3.93)$ & $14.2(5.12)$ & .28 \\
\hline Sexual & $14.9(3.72)$ & $15.8(3.34)$ & .25 & $14.8(5.27)$ & $15.5(3.81)$ & .15 \\
\hline \multicolumn{7}{|l|}{ RRPQ-GE } \\
\hline Physical & $21.3(4.17)$ & $22.1(7.61)$ & .13 & $21.2(2.26)$ & $20.9(7.43)$ & .05 \\
\hline Psychological & $21.9(6.68)$ & $20.8(3.36)$ & .20 & $21.3(5.88)$ & $19.8(5.80)$ & .25 \\
\hline Sexual & $20.7(2.48)$ & $22.7(8.32)$ & .32 & $19.9(5.95)$ & $21.4(5.84)$ & .25 \\
\hline
\end{tabular}

Note: RRPQ = Reactions to Research Participation Questionnaire; $\mathrm{PF}=$ participation factor; $\mathrm{PB}=$ personal benefits; $\mathrm{PD}=$ perceived drawbacks; $\mathrm{ER}=$ emotional reactions; $\mathrm{GE}=$ global evaluation.

a. $n=33$; b. $n=44$; c. $n=67$; d. $n=10$; e. $n=36$; f. $n=41$; g. $n=75$; h. $n=108$; i. $n=152$; j. $n=31$; k. $n=41$; I. $n=142 . * p<.05 . * * p<.01$. *** $p<.00$ I.

For women, no differences were found between perpetrators reporting more frequent psychological and physical aggression and perpetrators reporting less frequent psychological and physical aggression. The only significant difference was for perpetrators of sexual aggression, such that female perpetrators reporting more frequent sexual aggression had more positive PFs than female perpetrators reporting less frequent sexual aggression, $F(1,38)=$ $6.600, p<.05$.

Next, as displayed in Table 5, male victims reporting more frequent psychological aggression reported more positive PFs than victims reporting less frequent psychological aggression, $F(1,65)=4.886, p<.05$. Male victims reporting more frequent physical aggression reported more negative ER than victims reporting less frequent aggression, $F(1,34)=4.915, p<.05$. Finally, male victims reporting more frequent sexual aggression reported more positive 
Table 4. Differences Between Low- and High-Frequency Perpetrators on RRPQ Subscales

\begin{tabular}{|c|c|c|c|c|c|c|}
\hline & \multicolumn{3}{|c|}{ Men } & \multicolumn{3}{|c|}{ Women } \\
\hline & $\begin{array}{c}\text { Low } \\
\text { perpetrators, } \\
M(S D)\end{array}$ & $\begin{array}{c}\text { High } \\
\text { perpetrators, } \\
M(S D)\end{array}$ & d & $\begin{array}{c}\text { Low } \\
\text { perpetrators, } \\
M(S D)\end{array}$ & $\begin{array}{c}\text { High } \\
\text { perpetrators, } \\
M(S D)\end{array}$ & $d$ \\
\hline \multicolumn{7}{|l|}{ RRPQ-PF } \\
\hline Physical & I5.I (5.04) & $17.1(4.24)^{\mathrm{b}}$ & .42 & $15.4(2.56)^{g}$ & $15.9(3.56)^{\mathrm{h}}$ & .16 \\
\hline Psychological & $14.2(3.74)^{\text {c*** }}$ & $16.8(3.02)^{d}$ & .76 & $15.0(4.17)^{i}$ & $15.6(3.03)^{j}$ & .16 \\
\hline Sexual & $16.3(3.60)^{\mathrm{e}}$ & $15.9(2.63)^{f}$ & .12 & $12.9(5.89)^{\mathrm{k} *}$ & $16.3(3.69)^{\prime}$ & .69 \\
\hline \multicolumn{7}{|l|}{ RRPQ-PB } \\
\hline Physical & I2.I (3.4I)** & I $5.8(2.27)$ & 1.2 & $13.2(3.20)$ & I3.2(3.64) & .00 \\
\hline Psychological & $12.0(3.47)^{*}$ & $13.7(3.02)$ & .52 & $12.1(3.76)$ & I3.2(3.46) & .30 \\
\hline Sexual & $12.4(3.09)$ & $13.7(3.42)$ & .39 & II.0 (5.2I) & $13.1(3.16)$ & .48 \\
\hline \multicolumn{7}{|l|}{ RRPQ-PD } \\
\hline Physical & $21.4(5.53)$ & $21.5(3.54)$ & .02 & $21.9(4.09)$ & $20.6(4.52)$ & .30 \\
\hline Psychological & $20.8(5.30)$ & $22.1(3.50)$ & .28 & $21.9(6.06)$ & 21.7 (3.96) & .03 \\
\hline Sexual & $22.8(4.88)$ & $21.8(3.14)$ & .24 & I 8.0 (8.32) & $22.0(4.28)$ & .60 \\
\hline \multicolumn{7}{|l|}{ RRPQ-ER } \\
\hline Physical & $14.8(3.68)^{*}$ & $12.0(2.84)$ & .85 & 15.4 (3.69) & $14.7(3.34)$ & .19 \\
\hline Psychological & $15.9(3.40)^{*}$ & I4.I (3.50) & .52 & $15.9(4.39)$ & $15.2(3.40)$ & .17 \\
\hline Sexual & $15.7(3.48)$ & $14.0(3.86)$ & .46 & $13.9(6.40)$ & I $5.8(3.44)$ & .36 \\
\hline \multicolumn{7}{|l|}{ RRPQ-GE } \\
\hline Physical & $20.7(4.95)$ & $22.0(2.98)$ & .31 & $21.4(2.16)$ & $21.1(2.40)$ & .13 \\
\hline Psychological & $22.0(9.02)$ & $21.9(2.86)$ & .01 & $21.5(8.03)$ & $21.2(2.28)$ & .05 \\
\hline Sexual & $20.4(2.36)$ & $21.0(2.64)$ & .23 & I $8.8(7.86)$ & $21.2(1.87)$ & .42 \\
\hline
\end{tabular}

Note: RRPQ = Reactions to Research Participation Questionnaire; PF = participation factor; PB = personal benefits; $P D=$ perceived drawbacks; $E R=$ emotional reactions; $G E=$ global evaluation.

a. $n=18$; b. $n=15$; c. $n=34$; d. $n=33$.; e. $n=19$; f. $n=17$; g. $n=42$.; h. $n=33$.; i. $n=76$.; j. $n=76$;

k. $n=22 . ;$ I. $n=19 . ; *^{*}<.05$. **p $<.01$. $* * * p<.001$.

PB than victims reporting less frequent sexual aggression, $F(1,22)=7.155$, $p<.05$.

Finally, for female victims, the only significant difference was for psychological aggression, such that victims reporting more frequent psychological aggression reported more positive $\mathrm{PB}$ than victims reporting less frequent psychological aggression, $F(1,138)=4.385, p<.05$.

\section{Discussion}

The current study sought to determine the research reactions among college students to participating in dating violence research and to examine whether victims and perpetrators of dating violence had different experiences than 
Table 5. Differences Between Low- and High-Frequency Victims on RRPQ Subscales

\begin{tabular}{|c|c|c|c|c|c|c|}
\hline & \multicolumn{3}{|c|}{ Men } & \multicolumn{3}{|c|}{ Women } \\
\hline & $\begin{array}{l}\text { Low victims, } \\
M(S D)\end{array}$ & $\begin{array}{l}\text { High victims, } \\
M(S D)\end{array}$ & $d$ & $\begin{array}{l}\text { Low victims, } \\
\qquad M(S D)\end{array}$ & $\begin{array}{c}\text { High victims, } \\
M(S D)\end{array}$ & $d$ \\
\hline \multicolumn{7}{|l|}{ RRPQ-PF } \\
\hline Physical & $15.9(5.16)^{\mathrm{a}}$ & $16.3(2.42)^{\mathrm{b}}$ & .09 & $14.7(4.05)^{g}$ & $15.5(2.61)^{\mathrm{h}}$ & .23 \\
\hline Psychological & $14.9(4.53)^{c *}$ & $16.1(2.21)^{d}$ & .33 & I5.I (4.19) & $15.5(3.10)^{\mathrm{j}}$ & .10 \\
\hline Sexual & $16.5(1.71)^{\mathrm{e}}$ & $15.5(2.46)^{f}$ & .47 & $14.3(5.29)^{k}$ & $15.6(3.06)^{\prime}$ & .30 \\
\hline \multicolumn{7}{|l|}{ RRPQ-PB } \\
\hline Physical & I3.I (3.59) & I4.5 (2.8I) & .43 & I $2.4(3.92)$ & $12.6(3.70)$ & .05 \\
\hline Psychological & I2.I (3.48) & 13.7 (3.05) & .48 & $12.0(3.97)^{*}$ & I3.3 (3.45) & .34 \\
\hline Sexual & I2.I (2.60)* & $14.9(2.53)$ & 1.0 & $12.0(5.01)$ & $13.0(3.32)$ & .23 \\
\hline \multicolumn{7}{|l|}{ RRPQ-PD } \\
\hline Physical & $21.0(4.84)$ & $22.2(2.78)$ & .30 & $20.3(5.73)$ & $20.3(3.66)$ & .00 \\
\hline Psychological & $20.8(5.18)$ & 22.1 (3.64) & .29 & $21.2(5.93)$ & $22.0(4.26)$ & .15 \\
\hline Sexual & $22.1(3.26)$ & $21.6(2.93)$ & .16 & 19.8 (7.91) & $21.8(3.44)$ & .32 \\
\hline \multicolumn{7}{|l|}{ RRPQ-ER } \\
\hline Physical & $15.0(3.35)^{*}$ & $12.6(3.06)$ & .74 & $15.5(4.43)$ & $14.3(3.40)$ & .30 \\
\hline Psychological & I5.5 (3.58) & $14.5(3.43)$ & .28 & $15.7(4.52)$ & $14.9(3.4 I)$ & .09 \\
\hline Sexual & $15.6(3.96)$ & I2.8 (3.63) & .73 & 13.9 (5.72) & I5.2 (3.49) & .27 \\
\hline \multicolumn{7}{|l|}{ RRPQ-GE } \\
\hline Physical & 24.0 (II.5I) & $20.6(3.16)$ & .40 & $20.8(4.44)$ & $20.7(2.18)$ & .02 \\
\hline Psychological & $22.2(8.92)$ & $21.6(3.12)$ & .08 & $21.5(8.21)$ & $21.1(2.24)$ & .06 \\
\hline Sexual & $21.1(2.07)$ & $21.0(2.90)$ & .03 & $19.2(6.73)$ & $21.0(2.24)$ & .35 \\
\hline
\end{tabular}

Note: RRPQ = Reactions to Research Participation Questionnaire; $P F=$ participation factor; $\mathrm{PB}=$ personal benefits; PD = perceived drawbacks; $\mathrm{ER}=$ emotional reactions; $\mathrm{GE}=$ global evaluation.

a. $n=19 . ;$ b. $n=18 . ;$ c. $n=34$.; d. $n=34$.; e. $n=13$.; f. $n=12$.; g. $n=30$.; h. $n=67 . ;$ i. $n=73$.; j. $n=68$.; k. $n=$ 30.; I. $n=24 . ; p<.05$. **p $<.01$. **** $p<.001$.

nonvictims and perpetrators. Results showed an interesting pattern of findings with differences evident for men and women. A summary of findings is presented in Table 6. First, findings supported our hypothesis and showed increased positive benefits for female victims and perpetrators of physical and psychological aggression relative to their nonviolent counterparts (e.g., glad they were able to participate). This is consistent with research on battered women that has found positive experiences associated research participation (Johnson \& Benight, 2003) and is the first study to our knowledge to also demonstrate this reaction for perpetration reports. These findings have important implications for IRBs and the proper informed consent of research participants. IRBs should be informed that asking female participants to disclose their dating violence experiences is often perceived as valuable, and 
potential participants could be informed that they may find their research participation beneficial.

Consistent with their female counterparts, male perpetrators and victims reported more positive benefits from their research participation relative to nonvictims and nonperpetrators. Specifically, these individuals largely perceived more PB to their research participation (e.g., gained personal insight) and positive PFs. These findings indicate that, for men, dating violence research may have the benefit of providing participants with insight into themselves and personal relationships. This information should be disseminated to IRBs and potential research participants as possible benefits from research participation.

Among female participants, findings did not support our hypothesis that victims would report greater negative ER to research participation than nonvictims (e.g., became upset). It should be noted, however, that male victims of physical and psychological aggression and male perpetrators of physical aggression reported more mildly negative ER than individuals without dating violence exposure. It is interesting that male victims, and not female victims, had more negative ER. It is possible that male victims in the current study became more upset due to the stigmatization of male victimization, which goes against male gender norms. It is also possible that women did not become more emotionally upset because they may be more likely to share their violent experiences with family and friends than men (Jackson, Cram, \& Seymour, 2000). Thus, female victims may have already disclosed their experiences to others, reducing the emotional toll of retelling these experiences. Still, additional research is warranted to replicate these findings and determine why male victims, and not female victims, reported more negative ER. It should be stressed that the level of emotional distress reported by male victims was relatively low, suggesting that excessive distress was not present. Still, IRBs and research participants for dating violence studies should be informed that their participation may cause a minimal increase in emotional distress, and researchers should have adequate resources available for participants who become distressed.

In addition, female victims of physical aggression and female perpetrators of sexual aggression reported more PD to their research participation (e.g., question too personal) than their nonviolent counterparts. Thus, although women may not become more emotionally upset, they still may report experiencing negative reactions from their research participation, and it is possible that the sensitive nature of dating violence questions may be perceived as an intrusion into their personal lives and, thus, too personal. This may be especially true for questions pertaining to sexual aggression, as evident by results from the current study. It is interesting to note that male perpetrators 
Table 6. Summary of Significant Differences on Research Reactions

\begin{tabular}{|c|c|c|}
\hline & Men & Women \\
\hline \multicolumn{3}{|c|}{ Victims/nonvictims } \\
\hline Psychological & $\begin{array}{l}\text { Victims had more positive } \\
\text { PF and more negative ER }\end{array}$ & $\begin{array}{l}\text { Victims had more positive } \\
\text { PF }\end{array}$ \\
\hline Physical & $\begin{array}{l}\text { Victims had more positive } \\
\text { PF and PB and had more } \\
\text { negative ER }\end{array}$ & $\begin{array}{l}\text { Victims perceived greater } \\
\text { PD }\end{array}$ \\
\hline Sexual & No differences & No differences \\
\hline \multicolumn{3}{|c|}{ Perpetrators/nonperpetrators } \\
\hline Psychological & $\begin{array}{l}\text { Perpetrators had more } \\
\text { positive PB }\end{array}$ & $\begin{array}{l}\text { Perpetrators had more } \\
\text { positive PF }\end{array}$ \\
\hline Physical & $\begin{array}{l}\text { Perpetrators had more } \\
\text { positive PB and more } \\
\text { negative ER }\end{array}$ & $\begin{array}{l}\text { Perpetrators had more } \\
\text { positive PF and PB }\end{array}$ \\
\hline Sexual & $\begin{array}{l}\text { Perpetrators had more } \\
\text { positive PF and less PD }\end{array}$ & $\begin{array}{l}\text { Perpetrators perceived } \\
\text { greater PD }\end{array}$ \\
\hline \multicolumn{3}{|c|}{ Low- and high-frequency victims } \\
\hline Psychological & $\begin{array}{l}\text { High-frequency victims had } \\
\text { more positive PF }\end{array}$ & $\begin{array}{l}\text { High-frequency victims had } \\
\text { more positive PF }\end{array}$ \\
\hline Physical & $\begin{array}{l}\text { High-frequency victims had } \\
\text { more negative ER }\end{array}$ & No differences \\
\hline Sexual & $\begin{array}{l}\text { High-frequency victims had } \\
\text { more positive PB }\end{array}$ & No differences \\
\hline \multicolumn{3}{|c|}{ Low- and high-frequency perpetrators } \\
\hline Psychological & $\begin{array}{l}\text { High-frequency } \\
\text { perpetrators had more } \\
\text { positive PF and PB and } \\
\text { more negative ER }\end{array}$ & No differences \\
\hline Physical & $\begin{array}{l}\text { High-frequency } \\
\text { perpetrators had more } \\
\text { positive PB and more } \\
\text { negative ER }\end{array}$ & No differences \\
\hline Sexual & No differences & $\begin{array}{l}\text { High-frequency perpetrators } \\
\text { had more positive PF }\end{array}$ \\
\hline
\end{tabular}

Note: $\mathrm{PF}=$ participation factor; $\mathrm{PB}=$ personal benefits; $\mathrm{PD}=$ perceived drawbacks;

$\mathrm{ER}=$ emotional reactions.

of sexual aggression perceived fewer drawbacks to their research participation than nonperpetrators, opposite to their female counterpart's reactions. This indicates that participating in dating violence research may provide 
male participants with benefits above and beyond that of women. For example, it is possible that male participants are gaining insight into their relationships and/or appreciate disclosing their experiences without the fear of having negative repercussions. This could be one reason why male perpetrators of sexual aggression did not perceive more drawbacks relative to nonperpetrators. Additional research is needed to replicate this finding and explicitly determine why this gender difference exists.

When differences between victims and perpetrators of more frequent dating violence and victims and perpetrators of less frequent dating violence were examined, results showed an interesting pattern of findings. Only male perpetrators of more frequent psychological and physical aggression, and male victims of more frequent physical aggression, reported increased negative ER than individuals experiencing less frequent aggression. This suggests that men may be especially vulnerable to experiencing mildly distressing ER following their research participation, particularly as their experiences with dating violence increase in frequency. At the same time, however, more frequent victimization and perpetration experiences for men and women was associated with more positive research experiences when compared with individuals who had experienced less frequent dating violence. It is possible that disclosing each abusive experience helped participants to realize the harmful nature of their behaviors, providing them with personal insight into themselves and relationships. Additional research is needed to examine this possibility.

In interpreting the above findings, it is important to consider the study's limitations. The majority of participants were of non-Hispanic White descent, and the study was conducted in a university setting, limiting the generalizability of the findings. The reliance on a retrospective self-report measure for violence is problematic, as recall bias may have affected responses. Future research would benefit from using interview formats to assess for violence and determine if similar reactions to research participation are present for interview-based dating violence studies. In addition, our method of classifying victims and perpetrators based on one act of aggression may have been too conservative an approach, as individuals may not identify with these categories based on a single incident of aggression. Furthermore, the relatively small sample sizes for high- and low-frequency aggression groups may have precluded the identification of additional significant differences, which is supported by a number of medium to large effect sizes between these groups despite nonsignificant findings. Future research using large samples is needed to determine if this is indeed true. Finally, it is unknown if the mildly negative ER of participants continued or dissipated after completion of the study, although no participants sought assistance from the investigators at the 
conclusion of the studies. Thus, follow-up studies are needed to determine the long-term emotional effects of participating in dating violence research.

Overall, the current study adds to the literature by assessing participants' reactions to engaging in dating violence research. Findings showed that reports of dating violence experiences can be mildly distressing, primarily for men, and that dating violence questions may be perceived as too personal for some in the context of research participation. Yet the level of emotional distress reported was relatively minor, indicating that disclosure of dating violence experiences is not excessively distressing for participants. Caution should be taken when asking participants to complete measures on dating violence, and IRBs and potential participants should be fully informed about possible negative ER to participating in dating violence research. Benefits of participation were also evident for both victims and perpetrators, even as the frequency of aggression increased, suggesting that dating violence research may provide participants with $\mathrm{PB}$, such as insight into their life experiences and personal relationships. Taken as a whole, the current study suggests that the benefits of dating violence research may outweigh the potential risks both for the individual and for psychological science.

\section{Declaration of Conflicting Interests}

The authors declared no potential conflicts of interest with respect to the authorship and/or publication of this article.

\section{Funding}

This study was partially supported by a Grand Valley State University Faculty Research and Development Grant.

\section{Note}

1. Due to the number of analyses comparing frequency of perpetration/victimization between the high- and low-frequency groups, the analyses are not reported here. The full output is available from the first author on request.

\section{References}

Campbell, R., Adams, A. E., Wasco, S. M., Ahrens, C. E., \& Sefl, T. (2010). "What has it been like for you to talk with me today?": The impact of participating in interview research on rape survivors. Violence Against Women, 16, 60-83.

Carter-Visscher, R. M., Naugle, A. E., Bell, K. M., \& Suvak, M. K. (2007). Ethics of asking trauma-related questions and exposing participants to arousal-inducing stimuli. Journal of Trauma \& Dissociation, 8, 27-55. 
Cornelius, T. L., Shorey, R. C., \& Beebe, S. M. (2010). Self-reported communication variables and dating violence: Using Gottman's martial communication conceptualization. Journal of Family Violence, 25, 439-448.

Cornelius, T. L., Sullivan, K. T., Wyngarden, N., \& Milliken, J. C. (2009). Participation in prevention programs for dating violence: Beliefs about relationship violence and intention to participate. Journal of Interpersonal Violence, 24, 1057-1078.

Crowne, D. P., \& Marlowe, D. (1960). A new scale of social desirability independent of psychopathology. Journal of Consulting Psychology, 24, 349-354.

DePrince, A. P., \& Chu, A. (2008). Perceived benefits of trauma research: Examining methodological and individual difference factors in responses to research participation. Journal of Empirical Research on Human Research Ethics, 1556, 35-47.

Griffin, M. G., Resick, P. A., Waldrop, A. E., \& Mechanic, M. B. (2003). Participation in trauma research: Is there evidence of harm? Journal of Traumatic Stress, 16, 221-227.

Hines, D. A., \& Saudino, K. J. (2003). Gender differences in psychological, physical, and sexual aggression among college students using the Revised Conflict Tactics Scale. Violence and Victims, 18, 197-217.

Hirshon, J. M., Krugman, S. D., Witting, M. D., Furuno, J. P., Limcangco, M. R., Perisse, A. R., \& Rasch, E. K. (2002). Variability in institutional review board assessment of minimal-risk research. Academic Emergency Medicine, 9, 1417-1420.

Jackson, S. M., Cram, F., \& Seymour, F. W. (2000). Violence and sexual coercion in high school students' dating relationships. Journal of Family Violence, 15, 23-36.

Johnson, L. E., \& Benight, C. C. (2003). Effects of trauma-focused research on recent domestic violence survivors. Journal of Traumatic Stress, 16, 567-571.

Johnson, M. P., \& Leone, J. M. (2005). The differential effects of intimate terrorism and situational couple violence: Findings from the national violence against women survey. Journal of Family Issues, 26, 322-349.

Kaura, S. A., \& Lohman, B. J. (2007). Dating violence victimization, relationship satisfaction, mental health problems, and acceptability of violence: A comparison of men and women. Journal of Family Violence, 22, 367-381.

Logan, T. L., Walker, R., Shannon, L., \& Cole, J. (2008). Combining ethical considerations with recruitment and follow-up strategies for partner violence victimization research. Violence Against Women, 14, 1226-1251.

Newman, E., \& Kaloupek, D. G. (2004). The risks and benefits of participating in trauma-focused research studies. Journal of Traumatic Stress, 17, 383-394.

Newman, E., Willard, T., Sinclair, R., \& Kaloupek, D. (2001). Empirically supported ethical research practice: The costs and benefits of research from the participants' views. Accountability in Research, 8, 309-329. 
Resick, P. A., Iverson, K. M., \& Artz, C. E. (2009). Participant reactions to a pretreatment research assessment during a treatment outcome study for PTSD. Journal of Traumatic Stress, 22, 316-319.

Rhatigan, D. L., \& Street, A. E. (2005). The impact of intimate partner violence on decisions to leave dating relationships: A test of the investment model. Journal of Interpersonal Violence, 20, 1580-1597.

Shorey, R. C., Cornelius, T. L., \& Bell, K. M. (2008). A critical review of theoretical frameworks for dating violence: Comparing the dating and marital fields. Aggression and Violent Behavior, 13, 185-194.

Smith, P. H., White, J. W., \& Holland, L. J. (2003). A longitudinal perspective on dating violence among adolescent and college-age women. Journal of American Public Health Association, 93, 1104-1109.

Straus, M. A., Hamby, S. L., Boney-McCoy, S., \& Sugarman, D. B. (1996). The Revised Conflict Tactics Scale (CTS2): Development and preliminary psychometric data. Journal of Family Issues, 17, 283-316.

White, J. W., \& Smith, P. H. (2009). Covariaiton in the use of physical and seuxal intimate partner aggression among adolescent college-age men: A longitudinal analysis. Violence Against Women, 15, 24-43.

Wolfe, D. A., Wekerle, C., Scott, K., Straatman, A. L., Grasley, C., \& Jaffe, D. R. (2003). Dating violence prevention with at-risk youth: A controlled outcome evaluation. Journal of Consulting and Clinical Psychology, 71, 279-291.

\section{Bios}

Ryan C. Shorey is a graduate student in clinical psychology at the University of Tennessee, Knoxville. He received his MA in psychology from the University of Tennessee, Knoxville. His research interests include intimate partner violence broadly, with a particular interest in dating violence.

Tara L. Cornelius is an associate professor at Grand Valley State University, Allendale, Michigan. Her primary research interests include dating violence, prevention and intervention, and behavioral skills training for intimate partners.

Kathryn M. Bell is an assistant professor at Northern Illinois University, DeKalb. Her primary research interests include the assessment of risk factors associated with intimate partner violence (IPV) and adult sexual assault, interpersonal violence risk recognition, and behavioral modeling of IPV perpetration. 